\title{
Prevalence of Gingival Biotype in Correlation with the Morphology of Maxillary Central Incisors and Its Variation among Three Ethnic Groups of Malaysian Subpopulations
}

\author{
Kishor Tom
}

\begin{abstract}
The gingival perspective in restorative dentistry is important in harmonizing esthetics and biological function. In this regard, the gingival biotypes have been stated to be thick or thin. Patients with the thin biotype are more prone to recession, inflammation, and compromised soft tissue response. The correct recognition of gingival biotypes is important for the treatment planning process in restorative and implant dentistry. The purposes of the survey were to evaluate the prevalence of the gingival biotype in correlation with the morphology of maxillary central incisors and its variation among three ethnic groups of Malaysian subpopulations and the prevalence of different gingival biotypes in individuals with varying forms of maxillary central incisors.

Materials and methods: A total of 300 individuals who were periodontally healthy, visiting the outpatient department of AIMST Dental Institute, Kedah, Malaysia, in the age range of 18-50 years, participated in the survey. Then, 100 participants from each race, that is, Chinese, Malay, and Indian, were further subdivided into two groups based on age as group I (18-30 years) and group II (30-50 years). Three clinical parameters were recorded by one examiner. This included the crown width/crown length $(\mathrm{CW} / \mathrm{CL})$ ratio of the two central incisors, papillary height $(\mathrm{PH})$, and gingival thickness. The measurements were tabulated and evaluated.

Results: There was a highly significant correlation between gingival biotype and crown length and area of papilla with $p$ values of -0.002 and 0.013 , respectively. Significant correlation was found between area of crown and PH with $p$ values -0.013 and 0.016 . The results of discriminant function analysis showed that the average crown length was the best single determinant of biotype and area of papilla was the next best choice.

The thinner biotype was more prevalent in young Chinese and Malay population with medium forms of maxillary central incisors while the young Indian population had thicker biotypes and wide and short form of maxillary central incisors. The older group in both Chinese and Malay populations have no difference in their gingival biotype regardless of their crown form. In the older Indian population, gingival biotype is thicker with a short and wide form of maxillary central incisors. Decreased papillary height was observed in the thinner biotypes in younger Chinese and Malay populations but thicker in young Indian population.

Conclusion: Within the limits of the current investigation, the existence and correlation of different gingival biotypes and dentopapillary complex dimension has been confirmed. These findings can be utilized as objective guidelines for determining the biotype and response of gingiva to many dental operative procedures.

Keywords: Papillary height, Thick biotype, Thin biotype, Varying forms.

Journal of Oral Health and Community Dentistry (2021): 10.5005/jp-journals-10062-0119
\end{abstract}

\section{INTRODUCTION}

In recent years, the dimension of different parts of the masticatory mucosa, especially gingival thickness, has become a subject of considerable interest in clinical dentistry both from an epidemiological and a therapeutic point of view. To achieve the optimal planning of preventive and therapeutic management mainly in periodontology, periodontal biotype in patients is being identified. Normally, there is considerable intraindividual and interindividual variation in both width and thickness of the facial gingiva, a fact that gives rise to the assumption that different gingival phenotypes might exist in any adult population. The gingiva is that part of masticatory mucosa that surrounds the cervical portion of the teeth and acts as the covering of the alveolar housing. Clinicians would all agree that healthy gingiva would be firm, salmon pink in color, adjacent to the cemento-enamel junction (CEJ), and have knife-edged interdental papilla and fill the interproximal area fully.

It is important to differentiate the gingival biotype among populations because gingival biotype has a significant impact on
Dental Public Health, AIMST University, Sememling, Kedah, Malaysia

Corresponding Author: Kishor Tom, Dental Public Health, AIMST University, Sememling, Kedah, Malaysia, e-mail: kishortom@gmail.com How to cite this article: Tom K. Prevalence of Gingival Biotype in Correlation with the Morphology of Maxillary Central Incisors and Its Variation among Three Ethnic Groups of Malaysian Subpopulations. J Oral Health Comm Dent 2021;15(3):129-133.

Source of support: Nil

Conflict of interest: None

the outcome of restorative and regenerative therapy. Therefore, during treatment planning, it is important to recognize differences in gingival tissue. Different gingival biotypes respond differently to inflammation, restorative treatment, trauma, and parafunctional habits. Hence in clinical practice, the identification of the periodontal biotype is significant. It was suggested that gingival or periodontal diseases were more likely to occur in patients with a thin gingival biotype. Similarly, in implant restorations, the thick

() The Author(s). 2021 Open Access This article is distributed under the terms of the Creative Commons Attribution 4.0 International License (https://creativecommons. org/licenses/by-nc/4.0/), which permits unrestricted use, distribution, and non-commercial reproduction in any medium, provided you give appropriate credit to the original author(s) and the source, provide a link to the Creative Commons license, and indicate if changes were made. The Creative Commons Public Domain Dedication waiver (http://creativecommons.org/publicdomain/zero/1.0/) applies to the data made available in this article, unless otherwise stated. 
flat tissue biotype was an important factor for a successful aesthetic treatment outcome. ${ }^{1}$ In root-coverage procedures, a flap thickness of $0.8-1.2 \mathrm{~mm}$ was associated with a more predictable prognosis. ${ }^{2}$ Müller et al. coined the term "gingival or periodontal phenotype" to address a common clinical observation of great variation in thickness and width of facial keratinized tissue. ${ }^{3}$ Claffey and Shanley defined the thickness not more than $1.5 \mathrm{~mm}$ as a thin biotype whereas more than $2 \mathrm{~mm}$ would be a thick biotype. ${ }^{4}$ It is important to identify the gingival biotypes to help in better determination of the treatment outcome.

There are many methods to measure gingival thickness. The gingival thickness can be assessed by the direct method, ${ }^{5}$ probe transparency (TRAN) method, ${ }^{6}$ ultrasonic devices, ${ }^{7}$ and cone beam computed tomography (CBCT) scans. ${ }^{8}$ The use of simple methods to identify the gingival tissue biotype can help the clinician with better treatment planning and definitive treatment outcome. Kan et al.'s study had stated a simple method to differentiate between the gingival biotypes based on the transparency of the periodontal probe through the gingival margin. ${ }^{9}$

Hence, this survey was undertaken to determine the prevalence of gingival biotypes among three ethnic groups of Malaysian subpopulations as related to the varying forms of maxillary central incisors.

\section{Materials and Methods}

A total of 300 individuals visiting the outpatient department of AIMST Dental Institute, Kedah, Malaysia, in the age range of 18-50 years, had participated in the survey. This research was approved by the AIMST University Research Ethics Committee. Then, 100 participants from each race, that is, Chinese, Malay, and Indian were further subdivided into two groups based on age as group I (18-30 years) and group II (31-50 years). After the patients were grouped, informed consent was obtained. The selection criteria were fixed as follows:

\section{Inclusion Criteria}

1. Individuals in the age-group of $18-50$ years;

2. Individuals who are periodontally healthy; and

3. Subjects who are systemically healthy.

\section{Exclusion Criteria}

1. Subjects with fracture, crown, restorations, or fillings on anterior maxillary teeth;

2. Subjects with significant clinical signs of periodontal disease or clinical attachment loss (CAL);

3. Subjects with orthodontic treatment;

4. Subjects with malocclusion, such as rotations; and

5. Pregnant or lactating females.

Written consent was obtained from all the individuals who participated in the study before the start of the examination. All the selected participants were subjected to the inclusive criteria and exclusive criteria. Any participant who failed to meet the above criteria were eliminated from the examination. Three clinical parameters, namely, $\mathrm{CW} / \mathrm{CL}$ ratio, $\mathrm{PH}$, and gingival thickness, were considered and recorded by an examiner.

Firstly, the $\mathrm{CW} / \mathrm{CL}$ ratio of the right and left central incisors were measured with a calibrated scale periodontal probe. The width of the crown was measured as the border between the cervical and middle portion whereas the crown length was measured as the distance between the incisal length of the crown and the free gingival margin or CEJ on the midlabial surface of maxillary central incisors.

Secondly, $\mathrm{PH}$ was measured as the distance from the tip of the papilla to a line which joins the midfacial soft tissue margin of two adjacent teeth. The mean value was calculated.

Finally, gingival thickness (GT) was evaluated. GT was categorized as thick or thin at the site level. This evaluation was made according to the measurements with the help of periodontal probing into the sulcus at the midfacial aspect of the central maxillary incisors.

If the outline of the underlying periodontal probe is visible through the gingival tissue, it was categorized as thin (score 0). If it cannot be seen through the gingival, it was categorized as thick (score 1).

\section{Analysis of Data}

All participants were divided into Chinese, Indian, and Malay as per their ethnicity in the age range of $18-50$ years. The following pie charts show the percentage of male and female participants in this research according to their ethnicity (Figs 1 to 3 ).



Fig. 1: Pie chart showing the gender distribution of the Chinese population under study

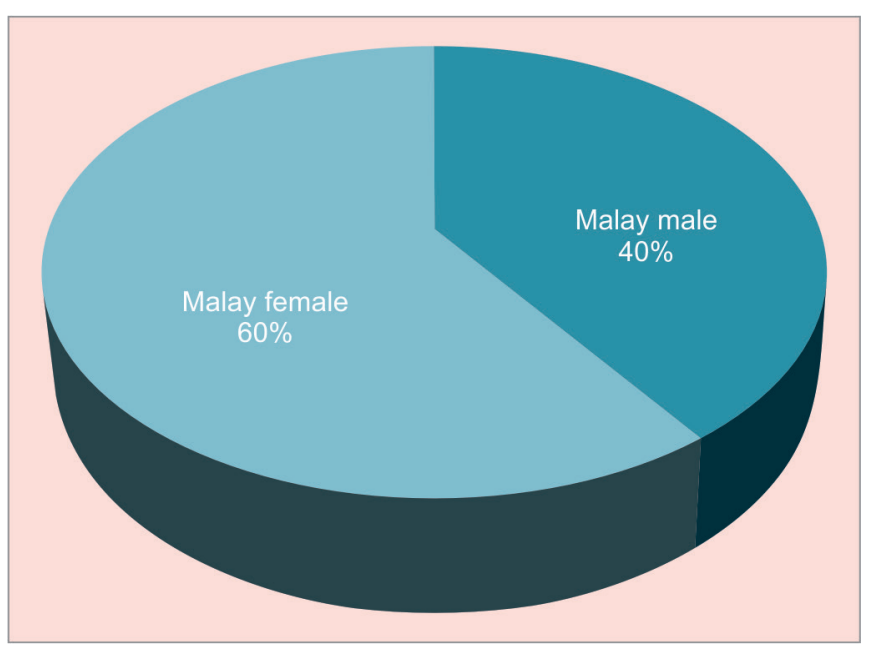

Fig. 2: Pie chart showing the gender distribution of the Malay population under study 




Fig. 3: Pie chart showing the gender distribution of the Indian population under study

Table 1: CW/CL, papillary height, and gingival biotype in the Chinese population

\begin{tabular}{|c|c|c|c|c|c|c|c|}
\hline \multicolumn{8}{|c|}{ Chinese population } \\
\hline & \multicolumn{3}{|c|}{$C W / C L(m m)$} & \multicolumn{2}{|c|}{ Papillary height $(\mathrm{mm})$} & \multicolumn{2}{|c|}{ Gingival biotype } \\
\hline & $0.6-0.79$ & $0.8-0.99$ & $1-1.19$ & $2-3.9$ & $4-5.9$ & 0 & 1 \\
\hline $\begin{array}{l}\text { Group I } \\
\text { (18-30 years) }\end{array}$ & $14(28 \%)$ & $28(56 \%)$ & $8(16 \%)$ & $36(72 \%)$ & $14(28 \%)$ & $31(62 \%)$ & $19(38 \%)$ \\
\hline $\begin{array}{l}\text { Group II } \\
\text { (31-50 years) }\end{array}$ & $14(28 \%)$ & $30(60 \%)$ & $6(12 \%)$ & $23(46 \%)$ & $27(54 \%)$ & $25(50 \%)$ & $25(50 \%)$ \\
\hline
\end{tabular}

Table 2: $\mathrm{CW} / \mathrm{CL}$, Papillary height, and gingival biotype in the Malay population

\begin{tabular}{|c|c|c|c|c|c|c|c|}
\hline \multicolumn{8}{|c|}{ Malay population } \\
\hline & \multicolumn{3}{|c|}{$\mathrm{CW} / \mathrm{CL}(\mathrm{mm})$} & \multicolumn{2}{|c|}{ Papillary height (mm) } & \multicolumn{2}{|c|}{ Gingival biotype } \\
\hline & $0.6-0.79$ & $0.8-0.99$ & $1-1.19$ & $2-3.9$ & $4-5.9$ & 0 & 1 \\
\hline $\begin{array}{l}\text { Group I } \\
\text { (18-30 years) }\end{array}$ & $20(40 \%)$ & 27 (54\%) & $3(6 \%)$ & $29(58 \%)$ & $21(42 \%)$ & $29(58 \%)$ & $21(42 \%)$ \\
\hline $\begin{array}{l}\text { Group II } \\
\text { (31-50 years) }\end{array}$ & $25(50 \%)$ & $24(48 \%)$ & $1(2 \%)$ & 27 (54\%) & $23(46 \%)$ & $25(50 \%)$ & $25(50 \%)$ \\
\hline
\end{tabular}

The above pie chart shows that $53 \%$ of Chinese female patients (53) and $47 \%$ of Chinese male patients (47) took part in this research. There were $60 \%$ and $40 \%$ of Malay female patients (60) and male patients (40) who participated in this research, respectively.

According to the above pie chart, a total of $54 \%$ Indian female and $46 \%$ male participated in this research.

Among the Chinese population, group I is from age 18 to 30 years old whereas group II is from age 31 to 50 years old. Each group consists of 50 participants. The frequency distribution of different biotypes between group I and group II has been analyzed (Table 1).

For the prevalence of varying central incisors (CW/CL ratio) in the age-groups in the Chinese population, we can see that $56 \%$ of group I have the range of $0.8-0.99 \mathrm{~mm}$ of the average $\mathrm{CW} / \mathrm{CL}$, $28 \%$ of population have the range of $0.6-0.79 \mathrm{~mm}$ of the average $\mathrm{CW} / \mathrm{CL}$, and $16 \%$ of population have the range of $1-1.19 \mathrm{~mm}$ of the average $\mathrm{CW} / \mathrm{CL}$. Furthermore, in group II, $60 \%$ of the population have the range of $0.8-0.99 \mathrm{~mm}$ of the average $\mathrm{CW} / \mathrm{CL}, 28 \%$ of the population have the range of $0.6-0.79 \mathrm{~mm}$ of the average $\mathrm{CW} / \mathrm{CL}$, and $12 \%$ of the population have the range of $1-1.19 \mathrm{~mm}$ of the average $\mathrm{CW} / \mathrm{CL}$.
Evaluation of $\mathrm{PH}$ between the age-groups in the Chinese population was also carried out. Among the group I participants, shorter $\mathrm{PH}$ is seen to be more prevalent with the range $2-3.9 \mathrm{~mm}$ (72\%) as compared with the longer form that ranges $4-5.9 \mathrm{~mm}$ (28\%). Among the group II individuals, higher prevalence of longer $\mathrm{PH}$ can be seen in the range of 4-5.9 $\mathrm{mm}$ (54\%) compared with the shorter form 2-3.9 mm (46\%).

In the third parameter, the gingival biotype, the prevalence of thinner form (62\%) is greater compared with the thicker form (38\%) in group I population. However, in group II population, the prevalence of the thinner form (50\%) is equal to or same as the thicker form (50\%).

Among the Malay population, group I is from age 18 to 30 years old whereas group II is from age 31 to 50 years old. Each group consists of 50 participants. The frequency distribution of different biotypes between group I and group II is as follows: Among the group I participants, thicker gingival biotype was observed to be more prevalent with score 1 (58\%) as compared with the thin form (42\%). Among the group II individuals, equal or same prevalence of thin biotype was found with a score $0(50 \%)$ as compared with the thick form (50\%) (Table 2). 
Gingival Biotype among Three Ethnic Groups in Malaysia

Table 3: $\mathrm{CW} / \mathrm{CL}$, papillary height, and gingival biotype in the Indian population

\begin{tabular}{|c|c|c|c|c|c|c|c|}
\hline \multicolumn{8}{|c|}{ Indian population } \\
\hline & \multicolumn{3}{|c|}{$C W / C L(\mathrm{~cm})$} & \multicolumn{2}{|c|}{ Papillary height $(\mathrm{mm})$} & \multicolumn{2}{|c|}{ Gingival biotype } \\
\hline & $0.6-0.79$ & $0.8-0.99$ & $1-1.19$ & $2-3.9$ & $4-5.9$ & 0 & 1 \\
\hline $\begin{array}{l}\text { Group I } \\
\text { (18-30 years) }\end{array}$ & $26(52 \%)$ & $24(48 \%)$ & 0 & $36(72 \%)$ & $14(28 \%)$ & $26(52 \%)$ & $24(48 \%)$ \\
\hline $\begin{array}{l}\text { Group II } \\
\text { (31-50 years) }\end{array}$ & 31 (62\%) & 19 (38\%) & 0 & 37 (74\%) & $13(26 \%)$ & $21(42 \%)$ & $29(58 \%)$ \\
\hline
\end{tabular}

The prevalence of varying central incisors (CW/CL ratio) in the age-groups in the Malay population is as follows: In group I, $40 \%$ of the participants have the range of $0.6-0.79 \mathrm{~mm}$ of the average $\mathrm{CW} / \mathrm{CL}, 54 \%$ of the participants have the range of $0.8-0.99 \mathrm{~mm}$ of the average $\mathrm{CW} / \mathrm{CL}$, and $6 \%$ of the participants have the range of $1-1.19 \mathrm{~mm}$ of the average CW/CL. However, in group II, $50 \%$ of the participants have the range of $0.6-0.79 \mathrm{~mm}$ of the average $\mathrm{CW} / \mathrm{CL}$, $48 \%$ of the participants have the range of $0.8-0.99 \mathrm{~mm}$ of the average $\mathrm{CW} / \mathrm{CL}$, and $2 \%$ of the participants have the range of $1-1.19 \mathrm{~mm}$ of the average $\mathrm{CW} / \mathrm{CL}$.

The evaluation of $\mathrm{PH}$ between the age-groups in the Malay population is as follows: Among the group I participants, shorter $\mathrm{PH}$ was observed to be more prevalent with range of 2-3.9 mm (58\%) as compared with the tall form which ranges $4-5.9 \mathrm{~mm}$ (42\%). Among the group II individuals, higher prevalence of short $\mathrm{PH}$ was found with the range of $2-3.9 \mathrm{~mm}(54 \%)$ as compared with the tall form (46\%).

Group I consists of participants who are aged from 18 to 30 years old whereas group II consists of participants from age 31 to 50 years old. There are 50 participants in each group. Among the group I subjects, thin gingival biotype was observed to be more prevalent with score 0 (52\%) as compared with the thick gingival (48\%) biotype. In group II individuals, $58 \%$ of the participants had the thick gingival biotype, which was more prevalent than the participants with thick gingival biotype (42\%). On comparing the prevalence of gingival biotypes between the age-groups in the Indian population, the thicker biotype has been more prevalent in older age-groups (Table 3).

For the prevalence of varying central incisors ( $C W / C L$ ratio) in the age-groups in the Indian population, $52 \%$ of the participants have the range of $0.6-0.79 \mathrm{~cm}$ of the average CW/CL whereas $48 \%$ of the participants have the range of $0.8-0.99 \mathrm{~cm}$ of the average CW/ $\mathrm{CL}$ in group I. In group II, $62 \%$ of the participants have the range of $0.6-0.79 \mathrm{~cm}$ of the average CW/CL whereas $38 \%$ of the participants have the range of $0.8-0.99 \mathrm{~cm}$ of the average $\mathrm{CW} / \mathrm{CL}$. However, no participant (0\%) was observed to have $C W / C L$ with $1-1.19 \mathrm{~cm}$ in the Indian population in Malaysia.

Besides, the evaluation of $\mathrm{PH}$ was also carried out between the age-groups in the Indian population. Among the group I individuals, shorter $\mathrm{PH}$ was found to be more prevalent with the range 2-3.9 $\mathrm{mm}(72 \%)$ as compared with the longer $\mathrm{PH}$ which ranges $4-5.9 \mathrm{~mm}$ (28\%). For the group II individuals, higher prevalence of shorter PH was observed with the range $2-3.9 \mathrm{~mm}(62 \%)$ as compared with the longer $\mathrm{PH}(38 \%)$. Hence, shorter PH was observed to be more prevalent than longer $\mathrm{PH}$ among the Indian population in Malaysia.

\section{Discussion}

Soft and hard tissue dimensions are important parameters that affect the outcome of periodontal and restorative treatments. Knowledge about these factors may help to better assess the need for soft or hard tissue augmentations and to avoid failures or complications, in particular in the esthetically critical area. Therefore, it would be useful to have reliable guidelines or surrogate objective parameters for the identification of critical cases with thin gingival and/or alveolar bone thickness, which might compromise the success of the treatment. Different parameters have been used to assess the gingival thickness or the so-called gingival biotype. However, the results and recommendations are controversial and none of the described parameters can be considered as the best or most reliable.

Up until now, there is no precise definition of how thick a thick biotype should be compared to a thin one. One of the reasons may be seen in the fact that thickness of the gingiva has been assessed at different vertical levels. ${ }^{2,9,10}$

The method of assessment of gingival biotype ranges from assessment with periodontal probe, visual examination, ultrasonic devices, or radiographic methods. The use of the periodontal probe for penetration within the sulcus was carried out in this study. Kan et al. in their study concluded that the gingival biotype identification with periodontal probe and direct measurement is not statistically different and is adequately reliable and objective. ${ }^{9}$ In contrast, Olsson et al.'s study demonstrated no significant association between visual and measured gingival tissue forms. ${ }^{10}$ Eghbali et al. also did a study to compare the assessment of gingival biotype in experienced and novice clinicians. They concluded that simple visual inspection could not be relied upon as an effective method irrespective of the clinician's experience. ${ }^{11}$

From the data collected, we can tell that Chinese and Malay have higher prevalence of medium $\mathrm{CW} / \mathrm{CL}$ with the thin gingival biotype for younger people whereas there is no difference in the gingival biotype for the older age-group regardless the CW/CL.

In addition, young people with shorter $\mathrm{PH}$ have the thinner gingival biotype in Chinese and Malay populations. However, there is again no difference in the gingival biotype among older people regardless the $\mathrm{PH}$.

In the Indian population, there is higher prevalence of wide and short crown regardless of their age. The younger age-group has the thinner gingival biotype, and the older age-group has the thicker gingival biotype.

Apart from that, both age-groups from the Indian population have a higher prevalence of shorter $\mathrm{PH}$. The younger people have again higher prevalence of the thin gingival biotype.

A study by Cook et al. evaluated various gingival parameters in patients having different periodontal biotypes. The results in their study documented no significant differences between tissue biotypes and crown height to width ratio, age, sex, and gingival margin position. ${ }^{12}$ In the present study, teeth with rotations and malpositions were excluded. But, on a wider range, most people are associated with slight malrotations. It should be emphasized that tooth position significantly can alter the gingival parameters. 
The relevance of this survey in periodontal surgeries and implant dentistry is emphasized. The thicker biotype prevents mucosal recession, hides the restorative margins, and camouflages the titanium implant shadows. It also prevents biological seal around implants, thus reducing the crestal bone resorption.

\section{CONCLUSION}

In this study, it has been demonstrated that gingival biotype varies in gender, age, and race among the population in our country. It was also found that in Malaysia, younger people are shown to have a thin gingival biotype when compared with the older agegroup. By understanding the nature of tissue biotypes, dentists can employ appropriate dental management and this will provide more favorable results after dental treatment.

\section{References}

1. Huang LH, Neiva RE, Wang HL. Factors affecting the outcomes of coronally advanced flap root coverage procedure. J Periodontol 2005;76:1729-1734.

2. $\mathrm{Fu} \mathrm{JH}, \mathrm{Yeh} \mathrm{CY}, \mathrm{Chan} \mathrm{HL}$, et al. Tissue biotype and its relation to the underlying bone morphology. J Periodontol 2010;81:569-574. DOI: 10.1902/jop.2009.090591.

3. Müller HP, Schaller N, Eger T, et al. Thickness of masticatory mucosa. J Clin Periodontol 2000;27(9):621-626.

4. Claffey N, Shanley D. Relationship of gingival thickness and bleeding to loss of probing attachment in shallow sites following nonsurgical periodontal therapy. J Clin Periodontol 1986;13:654-657. DOI 10.1111/j.1600-051x.1986.tb00861.x.

5. Greenberg J, Laster L, Listgarten MA. Transgingival probing as a potential estimator of alveolar bone level. J Periodontol 1976;47: 514-517. DOI: 10.1902/jop.1976.47.9.514.

6. De Rouck T, Eghbali R, De Bruyn $H$, et al. The gingival biotype revisited: Transparency of the periodontal probe through the gingival margin as a method to discriminate thin from thick gingiva.J Clin Periodontol 2009;36:428-433. DOI: 10.1111/j.1600-051X.2009.01398.x.

7. Müller HP, Barrieshi-Nusair KM, Könönen E. Repeatability of ultrasonic determination of gingival thickness. Clin Oral Investig 2007; 11(4):439-442. DOI: 10.1007/s00784-007-0125-0. Epub 2007 May 24.

8. Barriviera $M$, Duarte $W R$, Januario $A L$, et al. A new method to assess and measure palatal masticatory mucosa by cone beam computerized tomography. J Clin Periodontol 2009;36:564-568. DOI: 10.1111/j.1600-051X.2009.01422.x.

9. Kan JY, Morimoto T, Rungcharassaeng K, et al. Gingival biotype assessment in the esthetic zone: Visual versus direct measurement. Int J Periodontics Restorative Dent 2010;30:237-243. PMID: 20386780

10. Olsson M, Lindhe J, Marinello CP. On relationship between crown form and clinical features of the gingival in adolescents. J Clin Periodontol 1993;20:570-577. DOI: 10.1111/j.1600-051x.1993. tb00773.x.

11. Eghbali A, DeRouck T, De Bruyn H, et al. The gingival biotype assessed by experienced and inexperienced clinicians. J Clin Periodontol 2009;36:958-963. DOI: 10.1111/j.1600-051X.2009.01479.x.

12. Cook DR, Mealey BL, Verrett RG, et al. Relationship between clinical periodontal biotype and labial plate thickness: An in vivo study. Int J Periodontics Restorative Dent 2011;31:345-354. PMID: 21837300. 